\title{
Applicability of mHealth for Healthcare Management in Developing Countries: A Study in Bangladesh
}

\author{
M. Mozammel Hoque Chowdhury ${ }^{1}$ and Sharmin Jahan $^{2}$ \\ ${ }^{1}$ Department of Computer Science and Engineering \\ ${ }^{2}$ Department of Biochemistry and Molecular Biology \\ Jahangirnagar Universtity, Bangladesh \\ mozammel_ju@yahoo.co,sharmin.biochemist@yahoo.com
}

\begin{abstract}
Health care is one of the most important dependencies for economic growth and sustainability of a country. Most of the developing countries are facing the challenges of quality healthcare. However, recent advances in mobile communication technologies could play role in improving healthcare systems in developing countries. There is a great potential in using mHealth as one of the supportive systems within the healthcare sector to solve the inequalities in healthcare delivery between rural and urban hospitals/clinics. The emergence of smart mobile phones have created an unprecedented opportunity to provide health services to people in developing countries in an instantaneous, interactive and customized way. This research aims to evaluate the applicability, issues and challenges for implementation of mobile healthcare system in the developing world. To build up and promote mHealth services in the developing countries, this research has conducted a readiness assessment in some selected rural and urban hospitals/clinics of Bangladesh. Finally, a set of guidelines has been suggested to aid the implementation of a successful mobile healthcare system.
\end{abstract}

Keywords: mHealth, e-Health, Mobile Telecommunication, Telemedicine

\section{Introduction}

Mobile health, popularly known as mHealth is a subset of e-Health (electronic health) used for delivering health services to the customers using mobile devices [1]. It describes the application of mobile telecommunication and multimedia technologies in mobile and wireless health care delivery systems [2]. mHealth involves the use of wireless technologies to transmit and collect various health data and services which are easily accessible by health workers, practitioners, researchers, and patients through mobile devices. It can facilitate real-time monitoring of patients and direct provision of care via mobile telemedicine [3].

The term mHealth was coined by Robert Istepanian as use of "emerging mobile communications and network technologies for healthcare" [4]. A definition used at the 2010 mHealth Summit of the Foundation for the National Institutes of Health (FNIH) was "the delivery of healthcare services via mobile communication devices such as mobile phones, smart phones, PDAs, laptops and tablet PCs" [5].

According to the analyst firm Berg Insight [6], around 2.8 million patients worldwide were using a home monitoring service based on equipment with integrated connectivity at the end of 2012. Berg Insight forecasts that the number of home monitoring systems with integrated communication capabilities will grow at a compound annual growth rate of 26.9 percent between 2011 and 2017 reaching 9.4 million connections globally by the end of the forecast 
period. A growing percentage of health-related smartphone apps are available, and some estimates predict 500 million patients will be using such apps by the year 2015 [7].

According to a World Health Organization (WHO) report [8], higher-income countries show more mHealth activity than do lower-income countries. Countries in the European Region are currently the most active and those in the African Region the least active. The WHO notes an extreme deficit within the global healthcare workforce. According to WHO, 57 countries have critical shortages in health care workers, with a total deficit of 2.4 million health professionals worldwide. The study finds an average density of physicians, nurses and midwives per 1000 population of 0.64 in twelve countries of Africa. The density of the same metric is four times as high in the United States, at 2.6.

While mHealth certainly has application for industrialized nations, the field has emerged in recent years as largely an application for developing countries, stemming from the rapid rise of mobile phone penetration. Because of the size, portability, low power consumption and ability to operate with limited infrastructure, mobile phones are better platforms to provide health services in the developing countries. In this context, mHealth largely emerges as a means of providing greater access to larger segments of a population in developing countries, as well as improving the capacity of health systems in such countries to provide quality healthcare [9].

\section{Emerging Trends and Applications of mHealth}

The emerging trends and areas of applications of mHealth around the world include [10]:

- Emergency response systems (e.g., road traffic accidents, emergency obstetric care)

- Human resources coordination, management, and supervision

- Telemedicine diagnostic and decision support to remote clinicians

- Pharmaceutical Supply Chain Integrity \& Patient Safety Systems

- Clinical care and remote patient monitoring

- Health extension services

- Health services monitoring and reporting

- Health-related m-Learning for the general public

- Training and continuing professional development for health care workers

- Health promotion and community mobilization

- Support of long-term conditions, for example in diabetes self-management

A partnership for emergency communications was created on February 13, 2008, between United Nations Foundation and Vodafone Group Foundation. Such partnership will increase the effectiveness of the information and communications technology response to major emergencies and disasters around the world. A report of the UN Foundation and Vodafone Foundation presents seven application categories within the mHealth field [11]:

i) Education and awareness

ii) Helpline

iii) Diagnostic and treatment support

iv) Communication and training for healthcare workers

v) Disease and epidemic outbreak tracking

vi) Remote monitoring

vii) Remote data collection

Each application category as well as a specific project within the category has been described shortly. 


\subsection{Education and Awareness}

Education and awareness programs within the mHealth field are largely about the spreading of mass information from source to recipient through short message services (SMS). In education and awareness applications, SMS messages are sent directly to users' phones to offer information about various subjects, including testing and treatment methods, availability of health services, and disease management. SMSs provide an advantage of being relatively unobtrusive, offering patients confidentiality in environments where disease (especially HIV/AIDS) is often taboo. Additionally, SMSs provide an avenue to reach farreaching areas - such as rural areas-which may have limited access to public health information and education, health clinics, and a deficit of healthcare workers [11].

\subsection{Helpline}

Helpline typically consists of a specific phone number that any individual is able to call to gain access to a range of medical services. These include phone consultations, counseling, service complaints, and information on facilities, drugs, equipment, and/or available mobile health clinics [11].

\subsection{Diagnostic and Treatment Support}

Diagnostic and treatment support systems are typically designed to provide healthcare workers in remote areas advice about diagnosis and treatment of patients. While some projects may provide mobile phone applications - such as a step-by-step medical decision tree system-to help healthcare workers diagnosis, other projects provide direct diagnosis to patients themselves. In such cases, known as telemedicine, patients might take a photograph of a wound or illness and allow a remote physician diagnose to help treat the medical problem. Both diagnosis and treatment support projects attempt to mitigate the cost and time of travel for patients located in remote areas [11].

\subsection{Communication and Training for Healthcare Workers}

mHealth projects within the communication and training for healthcare workers subset involve connecting healthcare workers to sources of information through their mobile phones. This involves connecting healthcare workers to other healthcare workers, medical institutions, ministries of health, or other houses of medical information. Such projects additionally involve using mobile phones to better organize and target in-person training. Improved communication projects attempt to increase knowledge transfer amongst healthcare workers and improve patient outcomes through such programs as patient referral processes [11].

\subsection{Disease Surveillance, Remote Data Collection, and Epidemic Outbreak Tracking}

Projects within this area operate to utilize mobile phones' ability to collect and transmit data quickly, cheaply, and efficiently. Data concerning the location and levels of specific diseases (such as malaria, HIV/AIDS, TB, Avian Flu) can help medical systems or ministries of health or other organizations identify outbreaks and better target medical resources to areas of greatest need. Such projects can be particularly useful during emergencies, in order to identify where the greatest medical needs are within a country [11]. In the developing world, collecting field information is particularly difficult since many segments of the population are rarely able to visit a hospital, even in the case of severe illness. A lack of patient data creates an arduous environment in which policy makers can decide where and how to spend their (sometimes limited) resources. 


\subsection{Remote Monitoring and Treatment Support}

Remote monitoring and treatment support allows for greater involvement in the continued care of patients. Within environments of limited resources and beds-and subsequently a 'outpatient' culture - remote monitoring allows healthcare workers to better track patient conditions, medication regimen adherence, and follow-up scheduling. Such project has been used particularly in the area of medication adherence for AIDS and diabetes [11].

\section{Potentiality of mHealth in Developing Countries}

Health services are often inadequate in developing countries because they are neither accessible nor affordable and when they are accessible, they are often dysfunctional, low in quality, and unresponsive to the needs of clients [12]. Many developing countries like Bangladesh can't provide minimal health service to their people due to insufficient number of doctors, health care professionals and medical services. Although there are many clinics and hospitals are found in the rural and suburban areas but they are often ill-equipped. The inadequate infrastructure makes it more difficult to provide health care in rural and remote areas at the right time. If traveling cost of a patient to visit a medical specialist is higher than the cost of providing mobile consultation (m-consultation), then mHealth might be an economically viable solution. Table 1 outlines the dire situation of primary health care in developing countries in comparison with developed countries [13].

Table 1. Healthcare Indicators in Developed and Developing Countries

\begin{tabular}{|l|c|c|c|c|c|c|}
\hline Countries & $\begin{array}{c}\text { Infant } \\
\text { mortality } \\
\text { rate } \\
\text { (Per 1000) }\end{array}$ & $\begin{array}{c}\text { Maternal } \\
\text { Mortality } \\
(\text { Per100,000) }\end{array}$ & $\begin{array}{c}\text { Years of life } \\
\text { lost due to } \\
\text { communicabl } \\
\text { e disease (\%) }\end{array}$ & $\begin{array}{c}\text { Births attended } \\
\text { by skilled } \\
\text { health } \\
\text { personnel (\%) }\end{array}$ & Hospital beds & $\begin{array}{c}\text { Total Health } \\
\text { workers } \\
\text { (per 10000) }\end{array}$ \\
\hline India & 57 & 450 & 58 & 47 & 9 & 14 \\
\hline Mexico & 22 & 63 & 27 & 83 & 11 & 28 \\
\hline Pakistan & 78 & 320 & 70 & 54 & 12 & 12 \\
\hline Bangladesh & 52 & 570 & 60 & 20 & 3 & 5 \\
\hline USA & 5 & 8 & 10 & 100 & 32 & 125 \\
\hline UK & 7 & 11 & 9 & 99 & 39 & 75 \\
\hline
\end{tabular}

Within this context, mHealth has emerged as a viable solution to serve the pressing healthcare needs through its high reach and low cost mechanism by making health care more accessible, affordable and effective across the developing world. For many years, the mobile phone was not considered powerful tool to reduce the digital divide in health, but the dramatic penetration rate of mobile phones in the low and middle income countries over the last decade has increased the potential of mHealth services [14]. According to Varshney and Vetter [15], the current and emerging wireless technologies could improve the overall quality of service for users in both cities and rural areas, reduce the stress and strain on healthcare providers while enhancing their productivity, retention, and quality of life, and reduce the overall cost of healthcare services in the long-term.

Developing countries need to drive the development of mHealth to improve healthcare delivery systems in their countries. Bangladesh and other developing countries has the opportunity to use mobile telecommunication in a more integrated way in the healthcare sector to improve the quality, safety and efficiency in delivering healthcare services to the people. 


\section{Why this Study in Bangladesh}

Bangladesh is one of the most densely populated developing countries where most of the people are living in rural villages. There is a huge disparity in health care distributions between rural and urban areas. People are also suffering due to lack of medical expertise and health care facilities. In this scenario utilizing the limited resources, mHealth may be an easier and cheaper way to disseminate healthcare facilities to the rural areas. Providing medical care is the constitutional obligation of the government of Bangladesh. The national health policy emphasizes on "To develop a system to ensure easy and sustained availability of health services for the people, especially communities and urban areas" [16]. In order to meet the requirements of the overall objectives of the health sector, various programs were undertaken by Bangladesh government during the last decade.

In Bangladesh, with limited number of medical professionals, limited financial resources, high medical cost and poor quality of services, mobile health service represents a much needed extension of primary health care services. In Bangladesh, more than 20 million people are under mobile health service networks. The leading mobile phone operator Grameen Phone in collaboration with a telemedicine firm TRCL provides medical information services to the patients. It receives 10,000 calls every day to provide primary healthcare to the people [17].

Since, the main purpose of mHealth is to reach health care services to the patients who are isolated from specialized care, development of a successful mHealth system could help in delivering adequate and efficient healthcare in remote areas at an affordable cost. mHealth can provide services for 24 hours a day and seven days a week. In Bangladesh and other developing countries where access to medical services is restricted by distance and poor transportation and health care services are inadequate, mHealth offers a great opportunity and possibilities to distribute medical services by utilizing mobile telecommunication.

\section{Research Methodology}

The following steps will be performed to conduct this research work:

i) Literature study on mHealth applications and existing healthcare systems.

ii) Conducting an mHealth readiness assessment in the rural and urban hospitals/clinics of Bangladesh

iii) Expert opinion

iv) Data collection, and

v) Employment of the assessment results to compile an mHealth framework.

Data will be collected using different techniques which include group interviews, qualitative questionnaires, photographs, document analysis and expert opinions. The outcome of the assessment will lead to the compilation of the mHealth framework. Finally, a set of guidelines will be provided by the research study to aid the implementation of a successful mHealth system.

\section{Present Mobile Telecommunication Infrastructure in Bangladesh}

Bangladesh is a riverside country and most of the country's regions are remote areas. Therefore, its long route communication systems are mainly composed of microwave, UHF and VHF radio links [18]. The use of optical fiber is presently limited within some city areas. The country has a link to Europe with SEA-ME-WE-4 fiber optic submarine cable consortium connecting a total of 14 countries at 16 landing stations [19]. 
Mobile telecommunication sector in Bangladesh has been experiencing a huge boom in the last few years. Several private and public mobile telecommunication operators have established their network all over the country. Currently there are 6 mobile phone operators in Bangladesh. Bangladesh has a huge potential in WiMax and submarine cable which has attracted the foreign telecom operators. Many foreign investors are now interested to invest in telecom sector in Bangladesh [20, 21].

Cellular Phone has revolutionized the telecommunication infrastructure in Bangladesh. It is really amazing that within the last decade, mobile phone service has provided about hundred million people with telecommunication services. More than half of the population in Bangladesh at present has constant access to mobile telephony and the number is growing every day. The total number of Mobile Phone subscribers has reached 115.628 million at the end of April 2014 [20]. Figure 1 indicates the trend of growth of mobile telecommunication. In 2013, there are almost as many mobile-cellular subscriptions as people in the world, with more than half in the Asia-Pacific region (3.5 billion out of 6.8 billion total subscriptions). Mobile phone penetration rates stand at $96 \%$ globally; $128 \%$ in developed countries; and $89 \%$ in developing countries [22]. Figure 2 shows the mobile telecommunication status in the world.

Telecommunication Status in Bangladesh

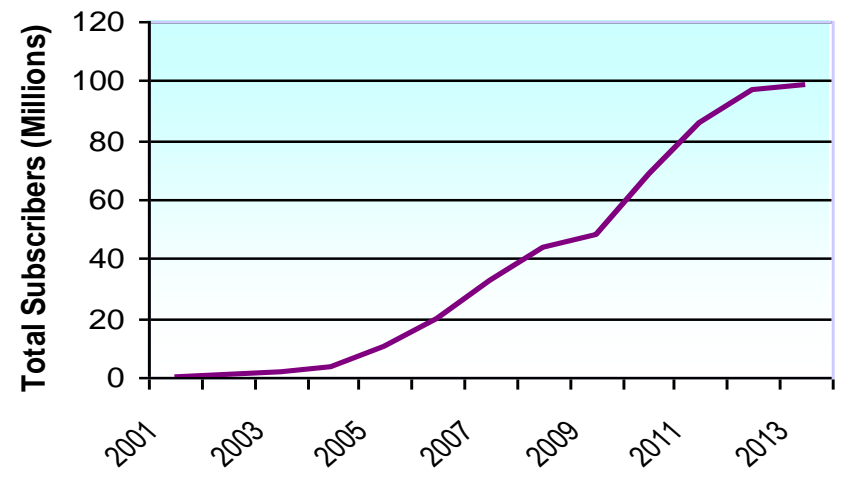

Figure 1. Mobile Telecommunication Status of Bangladesh

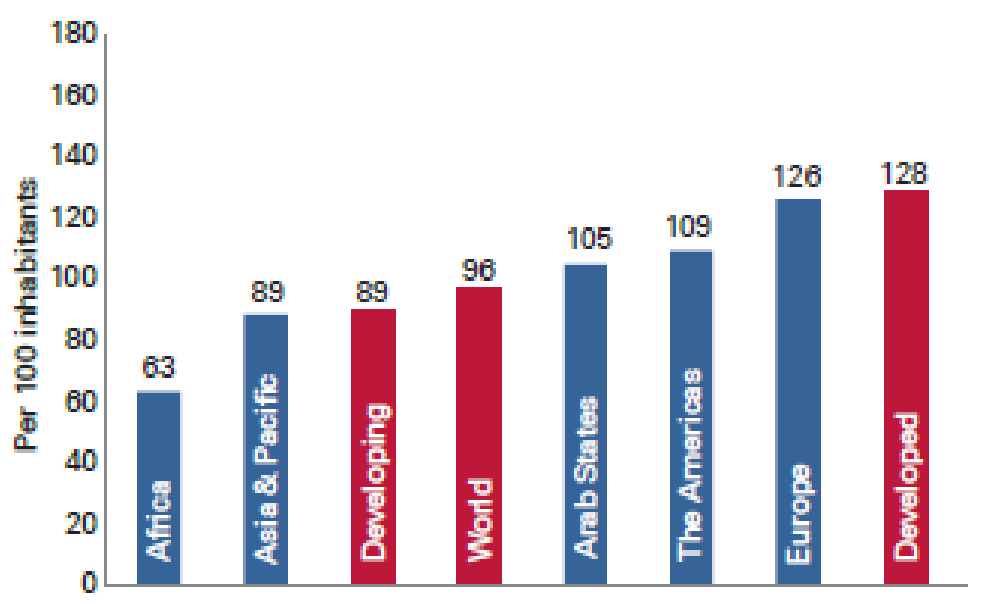

Figure 2. Mobile Telecommunication Status in the World 


\section{Challenges of Developing mHealth in the Developing Countries}

Bangladesh as well as other developing countries are facing various obstacles to the promotion and implementation of mHealth. This study has identified some major threats and challenges for developing mHealth in the developing world which include:

- Poor ICT infrastructure

- Lack of appropriate IT policy

- Lack of awareness of both government and citizens

- Inadequate human resource capacity

- Non-acceptability of IT systems

- Lack of coordination

- Low level of IT literacy

- Lack of IT training

- High-cost, lower liability of Internet access

- Lack of education

- Hassle in getting required service

- Lack of information

\section{A Sustainable mHealth Model}

Figure 3 shows a mHealth model sustainable for both urban and rural people of the developing countries since mobile phones have got the tremendous popularity and become the most usable communication tool in the developing world. The model has incorporated different stack holders of health care services.

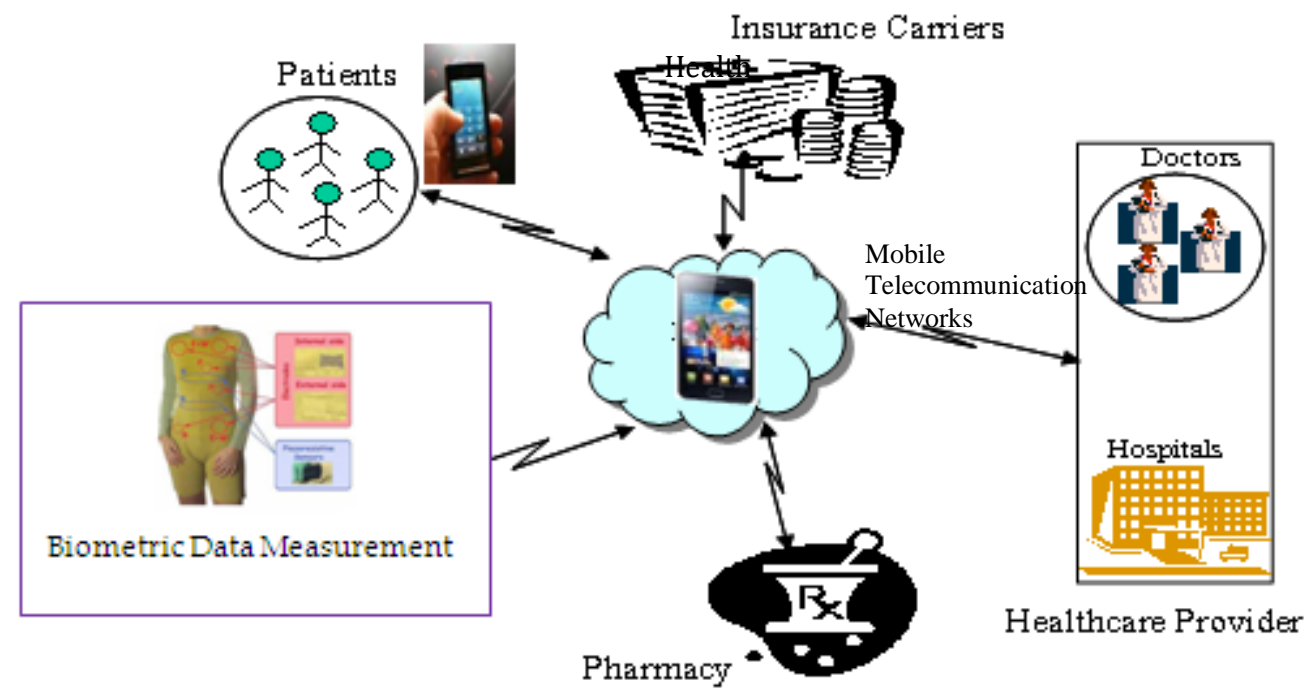

Figure 3. A Sustainable mHealth Model

\section{Recommendations}

Quality health service is critical for the poor people to access in developing countries. To cope with the issues and challenges, the rural poor in the developing world draw on indigenous knowledge and innovate through local experimentation and adaptation. The use of 
mobile communication technologies in health services can reduce the primary gap in health related needs that exist in daily life. In this context, functional quality of health information, affordable cost, availability of services, communication infrastructure, and easy to use information can play a predominant role in developing user perceived health care system. Technical awareness, network dynamism, service effectiveness and data delivery mechanism should be emphasized for raising user satisfaction. This study intends to recommend that the following policy initiatives are important conditions and facilitators for successful implementation of mHealth in the developing countries:

- Facilities should be built to mHealth services both in urban and rural areas. In this regard, steps can be taken for enhancing the country's technical setup with modern technology. Government as well as donor agencies, non-government organizations and other development partners of the country should participate in building up the necessary capacity in this area.

- Doctors, nurses, health professionals and health service providers are the most vital resources in promoting mHealth services to the door steps of the people. Since there is an acute shortage of qualified doctors and health professionals, short-term intensive training may be arranged.

- Modern and effective mobile telecommunication networks need to be built to support mHealth services.

- Everyone should have access to mobile communication, not just those who are literate and economically privileged. Special attention should be given to the needs of the disadvantaged and remote village people.

- Everyone should be encouraged and enabled to cope with mHealth services.

- Mobile telecommunication operators should be encouraged through providing governmental support and financial packages so that they could reduce the communication access cost for the user especially for the rural people.

- An integrated flexible and reliable nation-wide mobile communication system capable of voice, audio, video, data and graphics transmission should be ensured. National Information Infrastructure should be developed and it should be connected to Global Information Infrastructure through an information superhighway to create, collect and provide mHealth services to the world market.

\section{Conclusions}

Developing countries like Bangladesh are facing the challenges of quality healthcare. mHealth can be considered as one of the potential and supportive systems within healthcare sectors in the developing countries to improve the access, efficiency, effectiveness, and quality of clinical and business processes utilized by healthcare organizations, practitioners, patients, and consumers in an effort to cheer up the health status of patients and to face the emergency situations in some cases. This research evaluates the potentialities, issues and challenges for implementation of mobile healthcare system in the developing countries. This research proposes a sustainable mHealth framework for healthcare management in the developing world. This study has suggested some recommendations to develop a successful mHealth system through the outcome of an assessment conducted in selected rural and urban hospitals/clinics of Bangladesh. The proposed mHealth model could assist hospitals/clinics in rural and urban areas to deliver quality healthcare services, management of serious diseases and face the emergency situations of critical patients. 


\section{References}

[1] P. Mechael,, "The case for mHealth in developing countries", Innovations, MIT press, (2009).

[2] R. Istepanian, and J. Lacal, "Emerging Mobile Communication Technologies for Health: Some Imperative notes on mHealth" Paper presented at the 25th International Conference of the IEEE Engineering in Medicine and Biology Society, Cancun,Mexico, (2003).

[3] UN foundation \& Vodafone foundation, "mHealth for Development :The opportunity of mobile technology for healthcare in developing world", available from:http://www.vitalwaveconsulting.com/ insights/mHealth.htm, (2009).

[4] Istepanian, Robert; Laxminarayan, Swamy; Pattichis, Constantinos S., eds.. M-Health: Emerging Mobile Health Systems. Springer, (2005).

[5] T.Carol, "The mHealth Summit: Local \& Global Converge". caroltorgan.com. Retrieved July 29 , 2011.

[6] Berg Insight, "mHealth and Home Monitoring", M2M Research Series, Available at http: Ilwww.berginsight.com.

[7] J.A. Wolf, et al. "Diagnostic Inaccuracy of Smartphone Applications for Melanoma Detection." JAMA Dermatology 149, no. 4, (2013).

[8] World Helath Organization (WHO), "The world health report", Primary healthcare- now more than ever, Geneva, (2008).

[9] P.-G. Svensson, "eHealth Applications in Health Care Management”, EHealth International, (2002), pp. 1-2.

[10] P. Mechael, "WHO mHealth Review: Towards the Development of an mHealth Strategy", (2007).

[11] Vital Wave Consulting, mHealth for Development: The Opportunity of Mobile Technology for Healthcare in the Developing World. United Nations Foundation, Vodafone Foundation, (2009), p. 9.

[12] S. S. Andaleeb, "Service quality perceptions and patient satisfaction: a study of hospitals in a developing country", Social Science \& Medicine, vol. 52, no. 9, (2001).

[13] K. Brown, "Developing countries must plan road map for e-health", Conference Interview by Africa. Bellagio, Italy, (2008).

[14] P. Mechael, "The case for mHealth in developing countries, Innovations: Technology, Governance, Globalization", MIT Press Journal (online), (2009).

[15] U. Varshney, and R. Vetter, "Emerging Wireless and Mobile Networks", Communications of the Association for Computing Machinery, (2000), pp. 73-81.

[16] S. Akter,, J. D'Ambra and P. Ray, "User perceived services quality of mHealth services in developing countries", in the Proceedings of the Eighteen European Conference on conference on Information Systems, (2010); Pretoria, South Africa.

[17] G. Ivatury, J. Moore and A. Bloch, "A doctor in your pocket: Health hotlines in developing countries”, Innovations: Technology, Governance \& Globalization, MIT Press Journal (online), vol. 4, no. 1, (2009), pp. 119-153.

[18] M. Alam, and M. S. Islam, "E-Governance: Infrastructure and Implementation Challenges in Bangladesh", 10th International Conference on Computer and Information Technology, (2007); Bangladesh.

[19] A. Nessa, M. Al-Ameen, S. Ullah, and K. Kwak, "Applicability of Telemedicine in Bangladesh: Current Status and Future Prospects”, International Arab Journal of Information Technology, (2010), vol. 7, no. 2, pp. 138-145.

[20] Bangladesh Tele Regulatory Commission (BTRC), http://www.btrc.gov.bd/index.php.

[21] M. M. H. Chowdhury, "The Role of E-Governance towards Citizen Welfare in the Developing Countries: Perspective Bangladesh", International Conference of e-CASE 2009, (2009) January 810; Singapore.

[22] International Telecommunication Union (ITU), Geneva, Switzerland, The World in 2013: ICT Facts and Figures, http: Ilwww.itu.int/ict (2014).

\section{Authors}

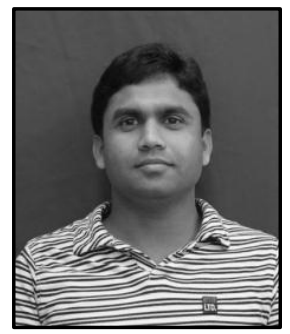

M. Mozammel Hoque Chowdhury is an Associate Professor in the Department of Computer Science and Engineering, Jahangirnagar University, Savar, Dhaka, Bangladesh. He received his B.Sc. (Honors) degree in Electronics and Computer Science and MS degree in Computer Science and Engineering from the same university. He has published 
around 30 articles in international and national journals and conference proceedings. His research interest includes: Image Processing, Computer Vision, Machine Intelligence, mHealth, Tele-health, e-Health, E-learning and E-governance.

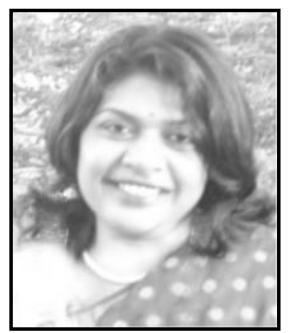

Sharmin Jahan is a Biochemist who obtained her B.Sc. (Honors) and MS (Research) in Biochemistry and Molecular Biology from Jahangirnagar University, Bangladesh. Her research interest includes: Health Science, Public Health, Clinical Biochemistry, Biotechnology, Animal Health, Human Nutrition, Food Technology, Industrial Biotechnology, Genetic Engineering and so on. 